\title{
Allocating Pooled Inventory According to Contributions and Entitlements
}

\author{
Yigal Gerchak*
}

\begin{abstract}
Inventory pooling, whether by centralization of stock or by mutual assistance, is known to be beneficial when demands are uncertain. But when the retailers are independent, the question is how to divide the benefits of pooling. e consider a decentralized inventorypooling scheme where a retailer's entitlements to the allocation during a shortage depend on his/her contributions to the pool. We derive the Nash equilibrium and specialize it to symmetric cases.
\end{abstract}

Keywords: inventory pooling; retailer contributions; entitlements; Nash equilibrium

Mathematics Subject Classification: 90, 91

Revised: January 9, 2015

\section{INTRODUCTION}

Inventory pooling in a decentralized system raises the issue of how to divide benefits among the parties, which is typically done using concepts from cooperative games (e.g., Gerchak and Gupta 1991; Hartman et al., 2000; Müller et al., 2002; Montrucchio et al., 2012); In particular, if the before-pooling optimal expected profits are $\pi_{1}^{*}\left(q_{1}^{*}\right)$ and $\pi_{2}^{*}\left(q_{2}^{*}\right)$, and the optimal expected profit after pooling is $\pi^{*}\left(q^{*}\right)$, the gain, $\pi^{*}\left(q^{*}\right)-\pi_{1}^{*}\left(q_{1}^{*}\right)-\pi_{2}^{*}\left(q_{2}^{*}\right)$ could be divided proportionally to $\pi_{1}^{*}\left(q_{1}^{*}\right)$ and $\pi_{2}^{*}\left(q_{2}^{*}\right)$. That allocation can be shown to belong to the (non-empty) core. We propose a very different "operational" non-cooperative scheme according to which the parties have entitlements that are increasing functions of their contributions to the pool rather than a typical division of benefits. The idea was proposed by Ben-Zvi and Gerchak (2012, sec. 11.5); but here, we analyze the consequences of a somewhat-modified scheme. The scheme can be shown to be beneficial to all parties vis-á-vis a no-pooling situation, namely is in core.

The scheme works as follows: each party (e.g., retailer) contributes a quantity of its choice to the pool. There is no inventory at the retailers' locales. The choice of these quantities is simultaneous. If the quantity of pooled inventory is not sufficient to

* Tel Aviv University, Department of Industrial Engineering, Israel, e-mail: yigal@post.tau.ac.il 
meet all realized demands, a retailer whose contribution exceeds its demand receives an allocation equal to its demand. The other retailer (whose demand exceeds its contribution) receives the rest of the inventory. If both demands exceed the respective contributions, each retailer receives its contribution. The scheme can be shown to be beneficial for all parties vis-ŕ-vis a no-pooling scenario. Mathematically (but not in type of motivations), our model is related to Shao et al. (2011).

The simultaneous selection of quantities to contribute to the pool is a noncooperative game. In a symmetric scenario (unit cost, revenue, demand distributions), we solve directly for the (common) order quantity. We provide an example.

\section{GENERAL MODEL}

Let $r_{i}$ be the unit revenue and $c_{i}$ unit production cost of party $i, r_{i}>c_{i} \forall i$. The distributions of the independent demands, $X_{1}$ and $X_{2}$, are $F_{1}$ and $F_{2}$. The parties are simultaneously looking for their best contribution quantities $q_{1}$ and $q_{2}$. The actual allocations to the parties as a function of demand realizations $\left(x_{1}, x_{2}\right)$ are denoted by $a_{1}$ and $a_{2}$.

The policy (contract) is as follows.

If $x_{i} \leq q_{i}$, then $a_{i}=x_{i}$;

if, in addition, $x_{j} \leq q_{j}$ then $a_{j}=x_{j}$;

if $x_{j}>q_{j}$ and $x_{i}+x_{j} \leq q_{i}+q_{j}$, then $a_{j}=x_{j}$;

if $x_{j}>q_{j}$ and $x_{i}+x_{j}>q_{i}+q_{j}$, then $a_{j}=q_{i}+q_{j}-x_{i}\left(\leq x_{j}\right)$. [This is the case where inventory pooling helps party $j$ ].

If $x_{i}>q_{i}$ and $x_{j}>q_{j}$, then $a_{i}=q_{i}$ and $a_{j}=q_{j} . \|$

So party $i^{\prime} s$ expected profit is:

$$
\begin{aligned}
E_{i}=-c_{i} q_{i} & +r_{i}\left\{\int_{x_{i}=0}^{q_{i}} x_{i} \int_{x_{j}=0}^{q_{j}} f_{i}\left(x_{i}\right) f_{j}\left(x_{j}\right) d x_{j} d x_{i}\right. \\
& +\int_{x_{i}=q_{i}}^{q_{i}+q_{j}} \int_{x_{j}=0}^{q_{i}+q_{j}-x_{i}} x_{i} f_{i}\left(x_{i}\right) f_{j}\left(x_{j}\right) d x_{j} d x_{i} \\
& +\int_{x_{i}=q_{i} x_{j}=q_{i}+q_{j}-x_{i}}^{q_{i}+q_{j}}\left(q_{i}+q_{j}-x_{j}\right) f_{j}\left(x_{j}\right) f_{i}\left(x_{i}\right) d x_{j} d x_{i} \\
& +\int_{x_{i}=q_{i}+q_{j}}^{q_{j}} \int_{x_{j}=0}^{q_{j}}\left(q_{i}+q_{j}-x_{j}\right) f_{j}\left(x_{j}\right) f_{i}\left(x_{i}\right) d x_{j} d x_{i} \\
& \left.+\int_{x_{i}=q_{i}}^{\infty} \int_{x_{j}=q_{j}}^{\infty} q_{i} f_{i}\left(x_{i}\right) f_{j}\left(x_{j}\right) d x_{j} d x_{i}\right\}
\end{aligned}
$$


so:

$$
\begin{aligned}
d E_{i} / d q_{i}=-c_{i} & +r_{i}\left\{2 \bar{F}_{j}\left(q_{j}\right) \bar{F}_{i}\left(q_{i}\right)-q_{i} f_{i}\left(q_{i}\right) \bar{F}_{j}\left(q_{j}\right)\right. \\
& +q_{j} F_{j}\left(q_{j}\right)-q_{i} f_{j}\left(q_{j}\right) F_{i}\left(q_{i}+q_{j}\right) \\
& \left.+\int_{x_{i}=q_{j}}^{q_{i}+q_{j}} F_{j}\left(q_{i}+q_{j}-x_{i}\right) d x_{i}+F_{j}\left(q_{j}\right) \bar{F}_{i}\left(q_{i}+q_{j}\right)-q_{i} f_{j}\left(q_{j}\right)\right\}
\end{aligned}
$$

Note that $E_{i}$ is an explicit function of only $c_{i}$ and $r_{i}$. On the other hand, it depends on both $F_{i}$ and $F_{j}$.

In the symmetric case $\left(c_{1}=c_{2} \equiv c, \quad r_{1}=r_{2} \equiv r\right), F_{1}=F_{2} \equiv F$, where we will look for a symmetric equilibrium, $q_{1}=q_{2} \equiv q$, we have $(r>c)$

$$
\begin{aligned}
d E / d q=-c & +r\left\{2[\bar{F}(q)]^{2}-q f(q) \bar{F}(q)+q F(q)-q f(q) F(2 q)\right. \\
& \left.+F(q) \bar{F}(2 q)-q f(q)+\int_{q}^{2 q} F(2 q-x) d x\right\} \\
d E /\left.d q\right|_{q=0}=-c & +2 r>0 \Rightarrow q^{*}>0
\end{aligned}
$$

\section{UNIFORMLY DISTRIBUTED DEMANDS}

Here $X \sim U[0,1]$, so $0 \leq q \leq 1$.

If $q \leq \frac{1}{2}$, the optimality condition becomes:

$$
-c+r\left(-3 q^{2}-3 q+2\right)=0
$$

i.e., $3 q^{2}+6 q-4+\frac{2 c}{r}=0$.

So:

$$
q^{*}=1-\frac{\sqrt{21-\frac{6 c}{r}}}{3}\left(<\frac{1}{2}\right)
$$

If $q>\frac{1}{2}$, the optimality condition becomes:

$$
-c+r\left(\frac{9}{2} q^{2}-7 q+2\right)=0
$$

i.e., $q^{2}-14 q+4-\frac{2 c}{r}=0$

$$
\Rightarrow q^{* *}=7-\sqrt{45+\frac{2 c}{r}}
$$

However, $q^{* *}<\frac{1}{2}$. Thus, the solution in this range is either boundary $q=\frac{1}{2}$ or $q=1$. 


\section{CONCLUDING REMARKS}

In partnerships, the partners' entitlements to profits are often based on their ownership shares. We use a similar philosophy in allocating scarce inventories. That translates to a non-cooperative game.

Issues that were not explored in this context but might be of interest include:

1) Non-Linear productions costs (Gerchak and Schwarz, 2014).

2) Holding some inventory at the retailers' locales ("partial pooling"), possibly with transshipment costs from the pool.

3) More insight into the case of non-symmetric parameters.

\section{REFERENCES}

Ben-Zvi, N., Gerchak, Y., 2012. Inventory Centralization in a Single Period Setting when Shortage Costs Differ: Priority and Costs Allocation. In: J. Choi (ed.), Handbook of Newsvendor Problems: Models, Extensions and Applications, Springer.

Cho, S.-H., Tang, C.S., 2014. Capacity Allocation under Retail Competition: Uniform and Competitive Allocations. Operations Research, Articles in Advance.

Friedman, J.W., 1984. Game Theory with Applications in Economics, Oxford University Press.

Gerchak, Y., Gupta, D., 1991. On Apportioning Costs to Customers in Centralized Continuous Review Inventory Systems. Journal of Operations Management, 10, pp. 546-551.

Gerchak, Y., Schwarz, G., 2014. Supply Chain Coordination with Multiple Rerailers and Non-Linear Production Costs.

Hartman, B.C., Dror, M., Shaked, M., 2000. Cores of Inventory Centralization Games. Games and Economic Behavior, 31, pp. 26-49.

Montruccio, L., Norde, H., Özen, U., Scarsini, M., Slikker, M., 2002. Cooperative Newsvendor Games: A Review. In: J. Choi (ed.), Handbook of Newsvendor Problems, Springer.

Müller, A., Scarsini, M., Shaked, M., 2002. The Newsvendor Game has a non-Empty Core. Games and Economic Behavior, 38, pp. 118-126.

Shao, J., Krishnan, H., McCormick, S.T., 2011. Incentives for Transshipment in a Supply Chain with Decentralized Retailers. Manufacturing and Service Operations Management, 13, pp. 361-370. 